\title{
Sports engineering education
}

\author{
Sean Maw ${ }^{1}\left(\mathbb{C}^{-} \cdot\right.$ Thomas Allen $^{2}$
}

Published online: 13 October 2018

(c) International Sports Engineering Association 2018

A distinct profession is marked by unique knowledge, skills, tools, methods, and problems. The longevity of such a profession depends on the persistence of need for the practitioner's problem-solving abilities, as well as on systematic training and mentorship of apprentices.

In recent decades, the field of sports engineering has developed a suite of design and research problems which distinguish it from other branches of science and engineering. Along with these design and research problems have come the development of specialized analytical and experimental tools and methods. In this new century, we have also seen the beginnings of sports engineering programs in postsecondary education around the world. These have been the first tangible steps in labelled training and mentorship for our young profession.

This journal is also an important part of the cultural fabric of our profession. In an effort to further contribute to the profession's development, a call was made for papers focused on sports engineering pedagogy so that a Special Issue could be produced. The goal was to solicit papers that would help define, characterize, and develop a unique approach to training and apprenticeship in sports engineering.

Two high-quality papers of this nature are presented to you in this issue. One focuses on resources to facilitate teaching and learning in sports engineering programs. The other seeks to define a methodology for pedagogical research in our area. Most certainly, there is ample room for more high-quality publications that will help shape our field's training programs. Systematic comparisons of existing programs and their features would be valuable. Treatises on our unique curriculum topics could be very insightful. An examination of which teaching methods work best in sports engineering would also be helpful. These and countless other topics will be the fodder for further publications in "sports engineering pedagogy". Beginning with this issue, and on an ongoing basis, this journal will welcome rigorous, high-quality, high-impact papers in pedagogy that are specifically relevant to our field.

This is the start of an important journey for our profession; one that will help ensure its longevity and lasting relevance. It adds a new dimension to our journal that will provide a more solid foundation upon which we can build our growing community. We look forward to receiving and publishing your work on pedagogy in sports engineering, in the years to come.
Sean Maw

sean.maw@usask.ca

Thomas Allen

t.allen@mmu.ac.uk

1 Jerry G. Huff Chair in Innovative Teaching and Acting Coordinator of the Engineering Entrepreneurship Program, Ron and Jane Graham School of Professional Development, College of Engineering, University of Saskatchewan, 57 Campus Drive, 2A20.1, Saskatoon, SK S7N 5A9, Canada

2 Manchester Metropolitan University, John Dalton Building, Manchester Campus, Manchester, UK 